\title{
Intake and expenditure of calories by the elderly
}

\author{
By J. V. G. A. Durnin, Institute of Physiology, \\ University of Glasgow
}

I have listened with care to the several excellent papers presented today, dealing, in a wide sense, with 'nutrition'. In spite of all the information contained in these talks, my main impression is that there are large, fundamental gaps in our knowledge of 'nutrition and the elderly'. It is, therefore, perhaps fitting that the topic in which the gaps are most frequent and probably largest should come last. After all, calories are the most important of the nutrients and, so often, in nutritional research one assumes that, by this time, the important obvious things have been discovered.

The inadequacy of the data on calorie intake and expenditure by the elderly is not something that is relative and therefore represents an unsatisfactory state of affairs only to the specialist; it is but too clear to the most superficial reader of the relevant literature.

The FAO: Committee on Calorie Requirements (1957) stated the facts and were full of the best intentions-at least for others-'present knowledge of the influence of ageing on the quantity of food eaten and energy expenditure is deficient and further investigations are needed'.

It is a pious hope at least. At a symposium of this Society on Energy Expenditure in Man, 5 years ago, I delivered a short paper (Durnin, 1956) on 'Energy expenditure in the elderly'. If my paper today had been restricted to energy expenditure, I should have had no additions to make to what I said then, except to describe some more of our own work. It is a sobering thought that, in 5 years, apparently no-one else has considered this research topic important enough to study. Of course, it may not be that the subject is unimportant; man is a difficult animal to study, although not, I should have thought, more difficult than husky dogs, mountain goats, Persian mares, Arctic red foxes, Alaskan red squirrels, porcupines, brent geese and north-western crows-the metabolism of which animals has been measured with great care and attention to detail. But no doubt ageing human beings are rather more difficult to deal with than ageing mice or rats. On the other hand, there is no need for conjecture as to the applicability of the results found-human beings are human whereas rats, cats and mice unfortunately are not. Studies on food consumption are, happily, a little more frequent than those on energy expenditure, although elderly people form an almost negligible proportion of those investigated.

\section{Calorie requirements}

It is probably generally thought that the calorie requirements of elderly people are substantially smaller than those of comparable young adults, i.e. of similar physique, social status, occupation, domicile and activity. The extent of this difference, however, is hypothetical and may, indeed, occasionally be almost minimal. Reasons for a difference are easy to formulate and are well enough given by FAO: Committee on Calorie Requirements (1957). (I) The amount of physical activity 
may alter; (2) the composition of the body, or the weight, may change, which may lead secondarily to a change in the basal metabolic rate; (3) muscular efficiency may decrease.

To evaluate the possible effects of these factors, and especially the first and the last, we ought to try and classify differing degrees of 'elderliness'. To me, an elderly person is someone between, say, 60 or 65 and, say, 70 to 75 : ('elderly' the Concise Oxford Dictionary defines as 'getting old'); beyond 75, people are old. This paper is not about the 'aged' but about the 'elderly'. It is important to define our terms before we discuss the factors of changing amounts of physical activity, body composition and muscular efficiency, since these changes are much more marked in degree after the age of 70 than before. My own impression at present is that, although individual variability is very marked in this instance, physical activity changes little between the ages of 30 and $60-70$ in healthy people, if we exclude those in the ever-diminishing number of occupations necessitating much physical effort. For the great mass of people who lead an almost sedentary life, we probably do much the same at 60 as we do at 30 . Clark \& Dunne (1955), in their most interesting and useful inquiry, Ageing in Industry, give many illustrations of the ability of large groups of men to carry on their work after $6_{5}$, even in some fairly strenuous occupations.

Muscular efficiency would appear to decrease with ageing: our own studies (Durnin \& Mikulicic, 1956) and those of other authors (e.g. Norris, Shock \& Yiengst, I953, I955) seem to make this reasonably certain, even for simple actions like walking. However, if the physical work is done with little gross body movement, then the difference in muscular efficiency is less marked. Nevertheless, there is almost certainly some loss of precision in neuromuscular co-ordination. This lack of precision might then lead to an older person's requiring more energy for a particular task than would a younger person.

The third factor (to be considered along with physical activity and muscular efficiency) tending to change with age is the composition of the body. There may be a decrease in the amount of muscle and generally a slight diminution in the relative amount of active tissue; or so we are told. But there are few studies on subjects in the age range we are discussing which compel us to lend much credence to this view. It may be true, but at present it is mainly conjecture. So often, our views on the elderly are coloured by our knowledge of the old. What is frequently true is that there is a mean increase in weight in the population with ageing.

We come now to the apparent conclusion that these three factors we have mentioned (changes in physical activity, body composition and efficiency of muscular movements) might easily have the overall effect of causing little alteration in, or even of increasing, the total gross metabolism of the body with ageing. Incongruous though it may seem, it may be true in some groups of men, where the physical exertion of their work may vary little over decades; it is probably less commonly true in women where the physical task of housework usually diminishes in middle and later life. 
How frustrating it is to be compelled to deal with the problem of total energy metabolism in this hypothetical way. The fact is that the facts are almost nonexistent. Compilers of bibliographies know this well-the excellent bibliographical reference volumes on research problems of ageing, edited by Dr Nathan Shock ( $195 \mathrm{I}$, 1957) contain no section in the index on 'energy metabolism': there are many reports of studies on that relatively valueless measurement 'basal metabolism' but none on total energy metabolism.

\section{Energy expenditure}

We are trying to accumulate some information on the total daily energy expenditure of some elderly people, men and women. We have, thus far, investigated three groups of men, each group containing about twelve subjects, of mean age 6o, and working in various light and heavy engineering factories; their mean energy output varied between 2700 and $3300 \mathrm{kcal} /$ day. Four separate groups of housewives, of approximately the same number of subjects per group as the men, have also been studied; some of them lived alone and some cared for their husbands and families. The mean energy expenditure of these groups of women varied from I $95^{\circ}$ to about $2300 \mathrm{kcal} / \mathrm{day}$. Data on such small numbers of subjects do not allow one to theorize satisfactorily about decrements of energy expenditure with ageing but there would appear little obvious difference from comparable younger people.

\section{Intake of calories}

When we come to deal with studies on measurement of calorie intake, we have a little more information at hand-but not much more and some of it of questionable value. How much credible data on calories do we obtain from the dozens of reports published each year on, as a random example, the diets of 273 families comprising Ior 4 individuals, where an investigator interviews the housewife once; or from the surveys involving questionnaires, $24 \mathrm{~h}$ recall, and so on-again $\mathrm{I}$ instance one on 'older workers' where (I quote) 'a record of the food eaten during 24 hrs.' was kept by 1439 men and 201 women, aged 64 ; the results are apparently of such questionable value that they are not even detailed by the authors. Another instance is the intakes of calories by elderly women estimated from the National Food Survey. Baines \& Hollingsworth (1955) quote values of $2900 \mathrm{kcal} / \mathrm{day}$ for women of mean age 60 years. Since that date similar results would seem to have been repeatedly obtained in subsequent surveys by N.F.S. investigators, although, in our experience, trained dietitians carrying out an idealized National Food Survey do not find equivalent values (unpublished results). Such improbably high results only serve to throw doubt on the worth of the surveys. At the other extreme, calorie intakes of between 500 and $1500 \mathrm{kcal} /$ day (Pyke, Holmes, Harrison \& Chamberlain, I 947) have been quoted for elderly women living in their own homes. Somewhere in between these probably lies the true mean intake for most elderly people. Bransby $\&$ Osborne (1953) found that the mean intake of men in Sheffield aged between 65 and 75 was about $2100 \mathrm{kcal} / \mathrm{day}$ and of women, about the same age, 1700-1800 $\mathrm{kcal} / \mathrm{day}$. 
Recently, a rather popularized account has been published of some very extensive nutritional surveys in the U.S. in a booklet called Nutritional Status U.S.A. edited by Dr Agnes Fay Morgan (1959). Unfortunately, I have found it difficult to trace the original scientific papers detailing the studies on the elderly. Some 600 men and about 3000 women aged somewhere between 20 and 80 and living throughout thirty-nine of the then forty-eight states, were investigated from the viewpoint of 'nutritional status'. Diet surveys, of one kind or another, were done on an unspecified number of these subjects during an II-year period, from 1947 onwards. The mean calorie intake of about 600 women aged 50-59 was approximately $1800 \mathrm{kcal} /$ day and that of about 500 women aged $60-69$ about $1600 \mathrm{kcal} / \mathrm{day}$. The value for about 70 men aged 50-59 was approximately $2700 \mathrm{kcal} /$ day and for the same number of $60-69$ year olds about $2400 \mathrm{kcal} / \mathrm{day}$.

During the past year or two we have been attempting to study this problem systematically in Scotland, although necessarily on a small scale, and have now accumulated results on a number of elderly subjects, both men and women. The values for calorie intake, measured over 7 consecutive days by the individual weighedinventory method, agree roughly with the results $I$ have already mentioned for energy expenditure.

\section{Conclusion}

Perhaps, and finally, we ought now to consider some official recommendations of calorie requirements for elderly people. The FAO: Committee on Calorie Requirements (I957) recommend a calorie intake of $2800 \mathrm{kcal} /$ day for a man of age 55 , $65 \mathrm{~kg}$ in weight and living in a temperate environment. At age 65 , the recommended intake drops to $2500 \mathrm{kcal} /$ day. For a woman, aged 55 and $55 \mathrm{~kg}$ in weight, living in similar surroundings, the allowance is $2000 \mathrm{kcal} / \mathrm{day}$ and at 65 it is $\mathrm{r} 800 \mathrm{kcal} / \mathrm{day}$. The equivalent recommendations of the (U.S.A.) National Research Council: Food and Nutrition Board (1958) are, for men, at age 55, $2600 \mathrm{kcal} /$ day and at age 65 $2350 \mathrm{kcal} /$ day and, for women, $1900 \mathrm{kcal} /$ day at 55 and $\mathrm{I} 750 \mathrm{kcal} /$ day at 65 .

It is obvious that there is less disagreement between suggested calorie requirements and intakes found experimentally for women than for men, but possibly it is so because of the smaller range of the values. For women, the FAO and N.R.C. recommendations fit in fairly well with our own findings, and with those of Bransby \& Osborne (I953), and not too badly with those of the large American studies. However, until a much larger number of really reliable surveys on the intake and expenditure of calories by the elderly are made, we shall have to continue theorizing in this most unsatisfactory manner.

The topic is of much practical importance. The elderly among us are increasing in number, and food is not always plentiful for them in all countries. One would think that their requirement of calories was an interesting and pertinent research project at present, although obviously not for physiologists. Perhaps we shall have to wait for the zoologists to complete their metabolic studies on Arctic foxes and brent geese and then turn to similar studies on man. 
Baines, A. H. J. \& Hollingsworth, D. F. (1955). Proc. Nutr. Soc. 14, 77.

Bransby, E. R. \& Osborne, B. (1953). Brit. F. Nutr. 7, 160.

Clark, F. le G. \& Dunne, A. C. (1955). Ageing in Industry. London: Nuffield Foundation.

Durnin, J. V. G. A. (1956). Proc. Nutr. Soc. 15, 89.

Durnin, J. V. G. A. \& Mikulicic, V. (1956). Quart. F. exp. Physiol. 41, 442.

FAO: Committee on Calorie Requirements. (1957). F.A.O. nutr. Stud. no. 15 .

Morgan, A. F. (1959). Bull. Calif. agric. Exp. Sta. no. 769.

National Research Council: Food and Nutrition Board. (1958). Publ. nat. Res. Coun., Wash., no. 589.

Norris, A. H., Shock, N. W. \& Yiengst, M. J. (I953). Circulation, 8, 52 I.

Norris, A. H., Shock, N. W. \& Yiengst, M. J. (1955). F. Geront. 10, I 45.

Pyke, M., Holmes, S., Harrison, R. \& Chamberlain, K. (1947). Lancet, 253, 46r.

Shock, N. W. (1951). A Classified Bibliography of Gerontology and Geriatrics. Stanford, California: Stanford University Press.

Shock, N. W. (1957). A Classified Bibliography of Gerontology and Geriatrics. Suppl. I. I949-1955. Stanford, California: Stanford University Press.

\title{
Nutrition and the elderly: Chairman's closing remarks
}

\author{
By R. E. Tunbridge, Department of Medicine, \\ The General Infirmary, Leeds
}

Professor Garry, in opening the discussion, referred to the importance of both nature and nurture in the study of man. Much of the discussion has been devoted to the problem of obesity and to the calorie requirements of the elderly. The frailty of the elderly stressed by Dr Boucher, particularly after the age of 70 when movement becomes limited, and secondary factors, strained resources, both financial and domestic, unsuitable housing and loneliness, all predispose to malnutrition. The difficulties of making a satisfactory dietary survey of the feeding habits of a sample population, let alone one amongst the elderly, were stressed. Miss Hollingsworth mentioned the tendency for the households studied to alter their feeding habits during the period of study as one such difficulty. Many elderly people lead physically restricted lives because of frailty and infirmity and in consequence have lessened energy requirements. Furthermore they are disinclined to bother with cooking so that they frequently only have a light breakfast, a cooked midday meal, and something later in the day. These facts are often forgotten when planning diets for the elderly. All the evidence submitted has indicated the need for a new assessment of the detailed requirements of the elderly and for the formulation of a national food policy. Mrs Newman commented critically on the present position on the lack of food knowledge amongst the public in general and on the difficulties of getting across a sound policy. The President's promise that the matter would be taken up by the Society has been enthusiastically received and fully justified the inclusion of the symposium in the Society's programme.

The hazards of obesity have been r epeatedly stressed,but the lack of agreement as to energy requirements for the elderly was in part due to wide individual variations. An earlier recommendation of FAO that a diminution in the calorie allowance of $7 \%$ for each decade after 25 years should form the basis of calculating calorie 